\title{
Gender-dependent changes in haematological parameters in patients with Cushing's disease before and after remission
}

\section{Alberto Giacinto Ambrogio', Martina De Martin'1, Paola Ascoli', Francesco Cavagnini ${ }^{1}$ and Francesca Pecori Giraldi ${ }^{1,2}$}

${ }^{1}$ Neuroendocrinology Research Laboratory, Istituto Auxologico Italiano IRCCS, Piazzale Brescia 20, 20149 Milan, Italy and ${ }^{2}$ Department of Clinical Sciences and Community Health, University of Milan, Piazzale Brescia 20, 20149 Milan, Italy
Correspondence should be addressed to F Pecori Giraldi Email

fpg@auxologico.it

\begin{abstract}
Objective: Glucocorticoids stimulate several steps in red blood cell (RBC) development; however, little is known on changes in erythroid parameters in patients with Cushing's disease. The aim of this study was to assess both RBC and white blood cell (WBC) parameters in a large cohort of patients with Cushing's disease and report on alterations in the active phase and after surgical remission.

Design and methods: A total of 80 patients with Cushing's disease (63 women and 17 men) were studied before and for up to 254 months' follow-up (mean follow-up $65.8 \pm 6.71$ months) after pituitary/adrenal surgery. Details of blood counts were reviewed and compared with data obtained from a database of healthy subjects.

Results: The RBC counts and haemoglobin levels were low in men with active Cushing's disease (over $80 \%$ of values in the lowest quartile) and four patients were overtly anaemic, whereas erythrocyte counts and haemoglobin levels were evenly distributed across the normal range in women with active Cushing's disease. Low erythroid parameters were linked to hypogonadism in men with Cushing's disease. Recovery in erythroid parameters occurred slowly after remission of hypercortisolism in men, in parallel with improvements in testosterone levels. Over $50 \%$ of patients with active disease presented increased WBC counts, irrespective of gender, and prompt normalisation within 1 month after surgery. Conclusions: Male patients with Cushing's disease present reduced RBC counts and haemoglobin levels, associated with low testosterone concentrations, which resolve over time after remission of hypercortisolism. Anaemia should therefore be regarded as another unfavourable feature in men with Cushing's disease.
\end{abstract}

\section{Introduction}

Cushing's syndrome presents with protean clinical manifestations due to the manifold consequences of excess cortisol secretion. However, while some features of hypercortisolism, for example osteoporosis or diabetes, are well known and have been extensively investigated, others remain to be fully characterised. One feature which has been little studied is altered haematopoiesis, although glucocorticoids are known to be important modulators of several crucial steps of red blood cell (RBC) development. In fact, glucocorticoids enhance proliferation of erythroid (c) 2014 European Society of Endocrinology Printed in Great Britain progenitor cells and participate in stress erythropoiesis following hypoxia or blood loss $(1,2,3,4)$. In clinical settings, glucocorticoids have been administered since the 1950s to patients with inherited RBC aplasias, such as Diamond-Blackfan anaemia (5), and to ameliorate anaemia in myeloproliferative disorders (6).

Historically, patients with Cushing's syndrome are often described as polycythaemic and plethoric and, indeed, 'round, red face' is a common description. Harvey Cushing reported that his first patient, Minnie G., 
presented $5.30 \times 10^{12} / 1$ erythrocytes and bright mucosae notwithstanding frequent nose and bowel bleedings (7). More recently, polycythaemia was the presenting feature in two patients with Cushing's disease $(8,9)$. However, a thorough evaluation of RBC counts in patients with Cushing's syndrome and their course after remission of hypercortisolism is yet to be performed. This feature is of particular interest given that RBC counts as well as Cushing's disease present gender-related features. RBC mass is greater in men than in women due to the effects of testosterone on erythropoiesis $(10,11)$ and, further, women of childbearing age, the age frame of Cushing's disease, often present slight anaemia due to menstrual blood losses. Conversely, although Cushing's disease is more prevalent in women than in men, several features of hypercortisolism are more severe in men than in women (12), suggesting a role for gonadal hormones. We therefore decided to analyse haematological alterations in men and women with Cushing's disease, both in the active disease phase and after cure.

\section{Subjects and methods}

The study population comprised 80 patients with Cushing's disease, 63 women and 17 men; age range between 15 and 62 years; mean $39.1 \pm 1.15$ years. Diagnosis of Cushing's syndrome was established according to standard diagnostic criteria $(13,14)$ and confirmed by pathology on transsphenoidal surgery specimens. Sixtyone patients were re-evaluated after remission of hypercortisolism: in 46 patients remission resulted from transsphenoidal surgery and in 15 patients from adrenalectomy (carried out as first-line surgery or after unsuccessful transsphenoidal surgery). The course of haematological parameters after unsuccessful pituitary surgery was evaluated in 16 patients. Corticosteroid replacement therapy was administered after transsphenoidal surgery starting at 25-37.5 mg cortisone acetate daily and then tapered over the following 1-71 months (mean length of treatment $16.37 \pm 2.11$ months). Neither men nor women were on gonadal steroid replacement therapy. Mean follow-up after surgery was $65.8 \pm 6.71$ months, range 7-254 months. Blood sampling was carried out shortly after surgery (i.e. 1-2 weeks) in all patients; patients in remission were re-evaluated every 2-3 months until full recovery of the pituitary-adrenal axis and then yearly once off steroid replacement therapy. Where available, results of testing for growth hormone $(\mathrm{GH})$ reserve by means of GH-releasing hormone $(\mathrm{GHRH})+$ arginine stimulation test were included (i.e. $\mathrm{GH}$ deficient if $\mathrm{GH}$ peak $<9 \mu \mathrm{g} / \mathrm{l})(15)$. Patients with persistent hypercortisolism after surgery were re-evaluated every 3-4 months until repeat pituitary surgery or adrenalectomy, radiotherapy or medical therapy. No patient was taking iron, vitamin B12 or folate supplementation and none referred piles or gastric ulcer. Informed consent was obtained from all patients for review of clinical charts and the study was approved by the Local Ethical Committee.

We reviewed blood cell counts, in particular, RBC count, haemoglobin and mean corpuscular volume (MCV) values, white blood cell (WBC) count and percentage of neutrophils and eosinophils. Standard blood chemistry tests, e.g. fasting blood glucose, electrolytes, total protein and cholinesterase, as well as hormonal parameter measurements, i.e. plasma adrenocorticotrophic hormone (ACTH) and serum cortisol, serum cortisol after $1 \mathrm{mg}$ dexamethasone overnight (i.e. OST), gonadal hormones (i.e. follicle-stimulating hormone, luteinizing hormone, total testosterone, $17 \beta$-oestradiol, progesterone), thyroidstimulating hormone and free thyroid hormones, had been performed on early morning serum/plasma samples after an overnight fast. Urinary free cortisol (UFC) was averaged over three 24-h urine collections. Review of laboratory indices of infections, e.g. elevated C-reactive protein, erythrocyte sedimentation rate, was carried out in order to exclude concurrent infection; blood cell counts were measured from a single blood sample at each evaluation.

\section{Assays}

Clinical chemistry platform was used to determine routine clinical analytes (Hitachi 917, Roche Diagnostics). Haematology was performed on Unicel DxH Coulter Cellular Analysis System (Beckman Coulter, Inc., Cassina de' Pecchi, Italy). Normal ranges for $\mathrm{RBC}$ and WBC parameters are haemoglobin $13.8-18.0 \mathrm{~g} / \mathrm{dl}, \mathrm{RBC}$ count $4.5-5.5 \times 10^{12} / 1$ for men and haemoglobin 11.9-16 g/dl, RBC 4.10-5.50×10 $12 / 1$ for women, MCV 80-96 fl, WBC count 4.3-10.5 $\times 10^{9} / 1$, neutrophils $40-75 \%$ and eosinophils $<6 \%$. Control data for haematological analyses were obtained from a database of over 3000 healthy normal subjects collected at our centre.

Serum cortisol was measured using radioimmunometric Coat-a-Count assay (Diagnostic Products Corp., Los Angeles CA, USA) and the same assay was used for UFC after extraction of dichloromethane; plasma ACTH was quantified by immunometric chemiluminescent assay (Elecsys, Roche Diagnostics). Normal ranges are 27.6-220.7 nmol/24 h for UFC, $138-689 \mathrm{nmol} / \mathrm{l}$ for 
serum cortisol and $2.2-11 \mathrm{pmol} / \mathrm{l}$ for ACTH. Total testosterone and other hormones were assayed by electrochemiluminescence (ECLIA, Roche Diagnostics). Total testosterone concentrations $<9.9 \mathrm{nmol} / \mathrm{l}$ were used as the criterion for the diagnosis of hypogonadism in adult men (16).

\section{Statistical analysis}

Mann-Whitney $U$ or Wilcoxon test were used for quantitative analyses, as appropriate; $\chi^{2}$ or Fisher's exact tests for analysis of qualitative data. The association between variables was tested by linear correlation. The comparisons yielding $P<0.05$ were considered significant. Values are expressed as mean \pm s.E.M.

\section{Results}

\section{Active Cushing's disease}

Men with Cushing's disease presented RBC parameters in the low-normal range and four patients were frankly anaemic (17). Distribution of values was significantly skewed compared with normative data with $81 \%$ of patients presenting values in the lowest haemoglobin quartile (i.e. $<14.7 \mathrm{~g} / \mathrm{dl}$ ) and $87.5 \%$ of patients with RBC counts in the lowest quartile (i.e. $<4.81 \times 10^{12} /$ l; Fig. 1). Mean haemoglobin and RBC values in men with Cushing's disease were significantly lower than in healthy subjects $(14.45 \pm 0.21$ vs $15.28 \pm 0.34 \mathrm{~g} / \mathrm{dl}$ and $4.47 \pm 0.13$ vs $5.06 \pm 0.13 \times 10^{12} / 1$ respectively, both comparisons $P<0.001)$. MCV was increased in men with Cushing's disease $(93.21 \pm 0.87$ vs $89.38 \pm 0.17 \mathrm{fl}, P<0.005)$ and $50 \%$ of patients presented values in the upper quartile of the normal range (i.e. $>96.3 \mathrm{fl}$ ).

Conversely, RBC counts were evenly distributed across the normal range in women with Cushing's disease with only a slight, non-significant increase in the proportion of patients in the upper quartile $(36.5 \%$ of patients with haemoglobin $>16.6 \mathrm{~g} / \mathrm{dl} ; 33 \%$ with $\mathrm{RBC}>6.67 \times 10^{12} / \mathrm{l}$ ). In keeping, mean haemoglobin levels in women with Cushing's disease were marginally higher than in controls $(13.75 \pm 0.17$ vs $13.16 \pm 0.25 \mathrm{~g} / \mathrm{dl}, P<0.05)$, whereas $\mathrm{RBC}$ counts were superimposable $(4.52 \pm 0.65$ vs $4.40 \pm$ $0.01 \times 10^{12} / \mathrm{l}$, NS; Fig. 1$)$. MCV was uniformly distributed across the normal range in women with Cushing's disease and average values were superimposable to the healthy population $(90.27 \pm 1.11$ vs $89.38 \pm 0.17 \mathrm{fl}, \mathrm{NS})$. Erythroid parameters were evaluated according to menstrual status in women with Cushing's disease, but no significant trend was observed (mean haemoglobin $13.2 \pm 0.28$, $13.83 \pm 0.35,14.05 \pm 0.35$ and $14.09 \pm 0.57 \mathrm{~g} / \mathrm{dl}$ in women with amenorrhoea, oligomenorrhoea, polimenorrhoea and normal menses respectively, NS).

No significant correlation was detected between RBC parameters and hypothalamic-pituitary-adrenal axis or thyroid function in either sex (data provided in
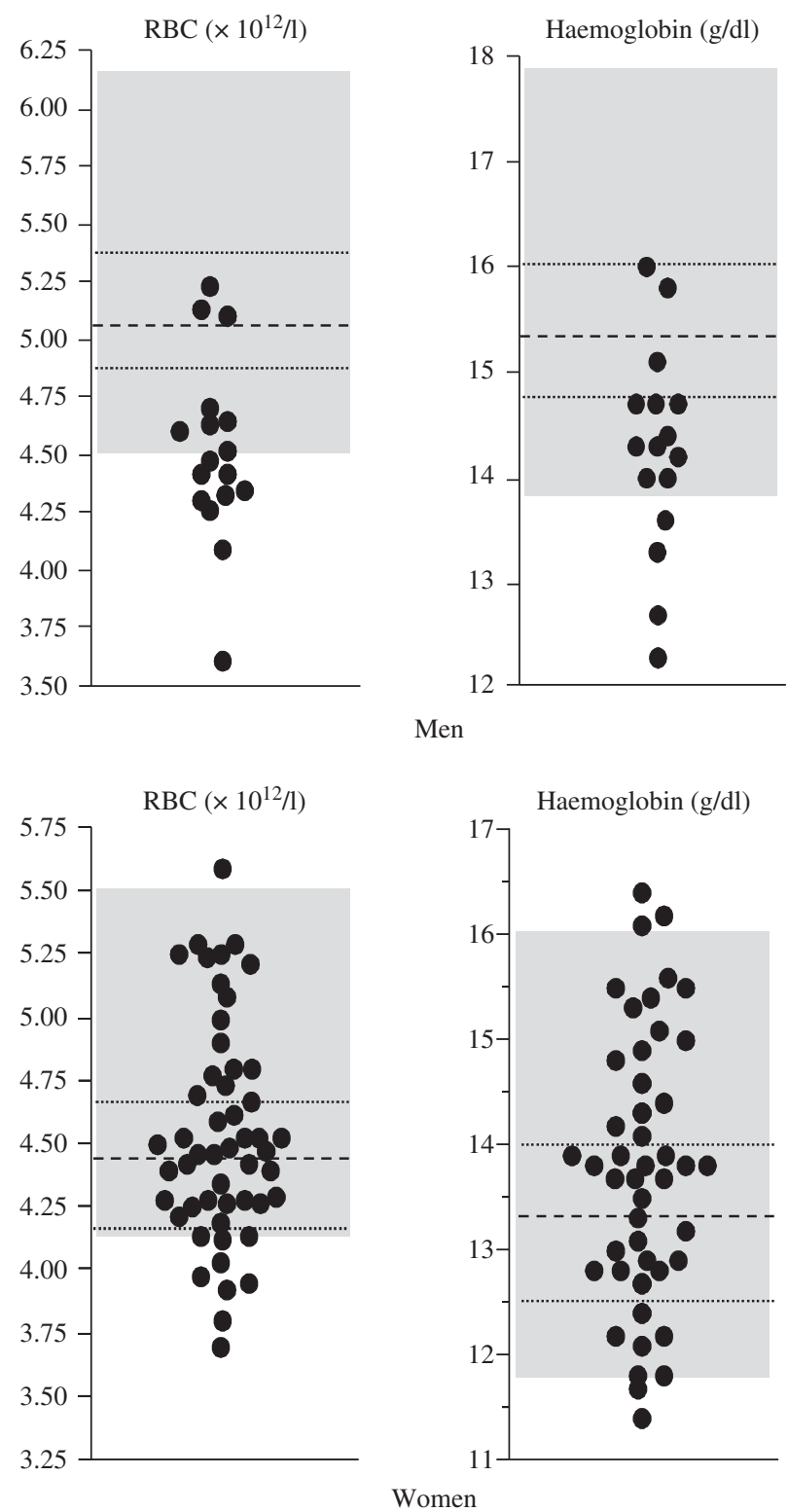

\section{Figure 1}

Red blood cell (RBC) counts and haemoglobin levels in female and male patients with active Cushing's disease. Normal range is represented by the grey area, dotted lines indicate $1^{\circ}$ and $3^{\circ}$ quartiles, dashed line indicates median in healthy control population. 
Supplementary Table 1 , see section on supplementary data given at the end of this article). Conversely, a significant correlation was detected between RBC parameters and testosterone levels in men with Cushing's disease $(r=0.69$, $P<0.05$ and $r=0.55, P<0.05$ for RBC and haemoglobin levels respectively). In fact, hypogonadism was diagnosed in all but three male patients $(81 \%$; average total testosterone $7.59 \pm 0.82 \mathrm{nmol} / \mathrm{l})$. No correlation was detected between testosterone levels and RBC or haemoglobin levels in women with Cushing's disease $(r=-0.05$, NS and $r=0.01$, NS respectively). Of note, only two women with active Cushing's disease presented increased testosterone levels (i.e. $>2.86 \mathrm{nmol} / \mathrm{l}$ ).

As expected, distribution of WBC counts was slanted towards the upper quartile of the normal range (i.e. $\left.>8.05 \times 10^{9} / 1\right), 52 \%$ of patients presented with counts above the normal range and 22 patients (32\%) with frank leukocytosis (i.e. $>11.5 \times 10^{9} /$; Fig. 2). Not surprisingly, mean WBC counts were higher in patients with Cushing's disease than in normal subjects $(9.56 \pm 0.31$ vs $7.39 \pm$ $\left.0.04 \times 10^{9} / 1, \quad P<0.001\right)$. No correlation was detected between WBC and UFC and other parameters of HPA activity (data provided in Supplementary Table 2, see section on supplementary data given at the end of this article). Reciprocal changes in the neutrophil and eosinophil populations were observed in patients with Cushing's disease, with $73 \%$ of patients presenting neutrophil percentages in the upper quartile of the normal range

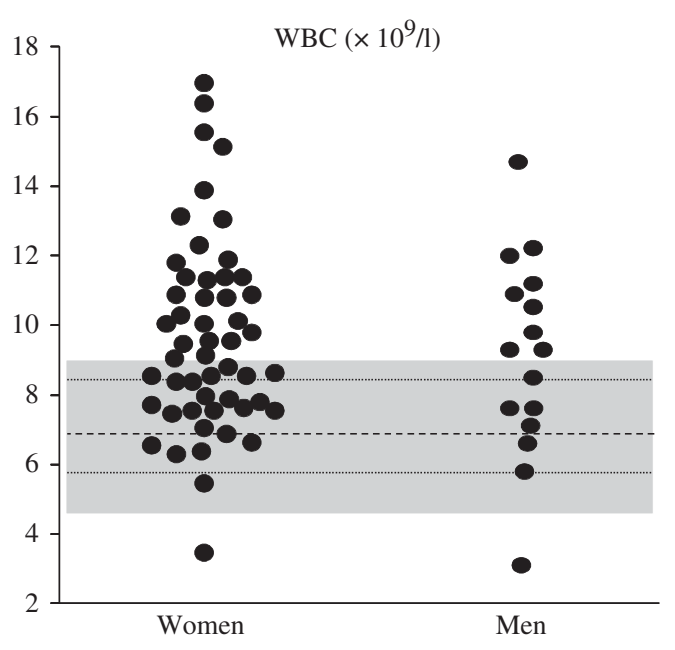

Figure 2

White blood cell (WBC) counts in female and male patients with active Cushing's disease. Normal range is represented by the grey area; dotted lines indicate $1^{\circ}$ and $3^{\circ}$ quartiles, dashed line indicates median in healthy control population. (i.e. $>63.7 \%$ ) and $27 \%$ frank neutrophilia (i.e. $>75 \%$ neutrophils). Mean neutrophil proportion was higher in patients with Cushing's disease than in controls (68.24 \pm 1.18 vs $57.03 \pm 0.18 \%, P<0.001$ respectively). Conversely, average eosinophil percentage was lower in patients than in healthy subjects $(1.35 \pm 0.18$ vs $2.86 \pm 0.04 \%, P<0.001)$ and distribution skewed towards the lowest quartile (71\% of patients with eosinophils $<1.5 \%$ ).

\section{Remission of hypercortisolism and persistent Cushing's disease}

A reduction in haemoglobin levels by $1.5-2 \mathrm{~g} / \mathrm{dl}$ was observed in both sexes within the first 2 weeks after pituitary surgery, regardless of its outcome, and levels fell to $12.5 \pm 0.18 \mathrm{~g} / \mathrm{dl}$ in women and $12.6 \pm 0.45 \mathrm{~g} / \mathrm{dl}$ in men (both comparisons $P<0.001$ compared with pre-surgery values). After surgery, men were again more anaemic than women ( $68 \%$ of men vs $18 \%$ women, $P=0.0036$ by Fisher's exact test). In keeping, normalisation of haemoglobin values after remission of Cushing's disease occurred within 1 year in women $(\sim 25 \%$ of measurements in each quartile 16 months after surgery), whereas slower recovery was observed in men with over $20 \%$ still presenting haemoglobin values below the normal range at the same time point (Fig. 3). Indeed, quartile distribution of haemoglobin values approached control distribution after $>2$ years in men in remission. Testosterone levels also increased slowly after surgery in men in remission and achieved full normalisation on average 24 months after surgery (Fig. 4). RBC counts were positively correlated with testosterone levels after successful surgery in male patients with Cushing's disease $(r=0.349, P<0.05)$ (Fig. 4). No impact of corticosteroid replacement therapy was observed on changes in RBC parameters. Of note, no patient was on testosterone replacement therapy. Assessment of GH status was available in 37 patients and revealed GH deficiency, i.e. $\mathrm{GH}$ peak $<9 \mu \mathrm{g} / \mathrm{l}$ after $\mathrm{GHRH}+$ arginine, in 16 out of 24 women and all 13 men, 2 years after surgery.

The MCV decreased significantly 3 months after surgery in both women and men $(86.7 \pm 0.99$ and $87.7 \pm 1.05$ fl respectively, $P<0.005$ vs pre-surgical values) and $12 \%$ of patients presented low MCV, in keeping with post-surgical blood loss and average RBC lifespan. MCV progressively normalised over the following months and was superimposable to pre-surgical values 1 year after surgery $(87.8 \pm 0.98$ and $88.7 \pm 0.74 \mathrm{fl}$ in women and men respectively).

WBC counts fell significantly within 4 weeks after surgery $\left(9.56 \pm 0.31\right.$ vs $\left.8.3 \pm 0.398 \times 10^{9} / 1, P<0.005\right)$ in 

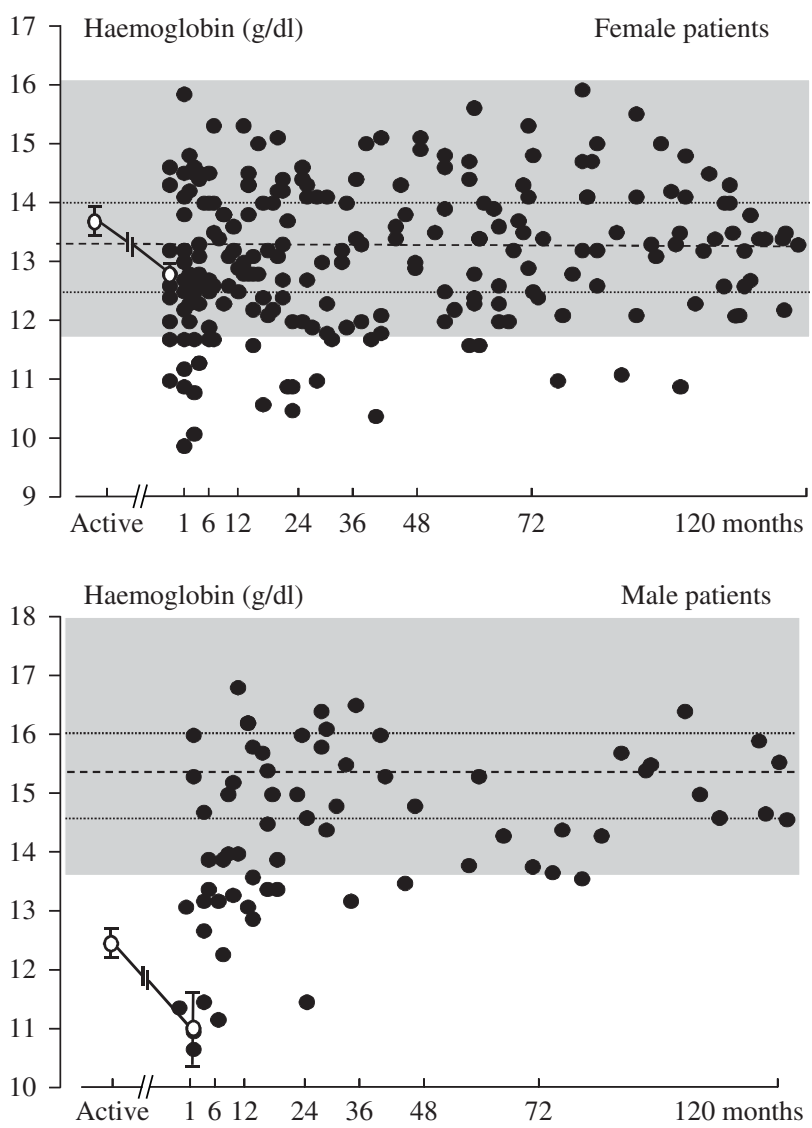

\section{Figure 3}

Haemoglobin values for patients in remission before and after surgery for Cushing's disease. Upper panel shows results of women; lower panel shows results of men. Empty circles depict mean \pm s.E.M. before and immediately after surgery. Normal range is represented by the grey area; dotted lines indicate $1^{\circ}$ and $3^{\circ}$ quartiles, dashed line indicates median in healthy control population.

patients in remission from Cushing's disease and thereupon the values continued to decrease $(7.12 \pm$ $0.415 \times 10^{9} / 1$ at 1 year and $6.18 \pm 0.274 \times 10^{9} / 1$ at 2 years after surgery). Reduction in WBC counts was associated with a reduction in neutrophils, as the mean percentage decreased from 68 to $58 \%(P<0.005)$ within the first month. Three months after surgery, 94\% of patients in remission presented normal WBC and neutrophils. At the same time, percentage of eosinophils increased from 1.3 to $2.7 \%(P<0.005)$. In contrast and not surprisingly, no significant differences were observed in WBC, neutrophils and eosinophils before and after surgery in patients with persistent hypercortisolism.

\section{Discussion}

The relationship between glucocorticoids and erythropoiesis is well-known and long standing, as documented by both experimental data and clinical experience. In fact, extensive in vitro studies have shown that glucocorticoids potentiate erythropoiesis $(4,18)$, enhance proliferation and self-renewal of erythroid progenitors (1), stimulate erythropoietin (19) and cooperate with its effects on progenitor cells $(20,21)$. Further, glucocorticoids are essential to stress erythropoiesis as glucocorticoid receptor-deficient mice are unable to mount an adequate erythroid response to hypoxia or blood loss, both in terms of erythroid-colony

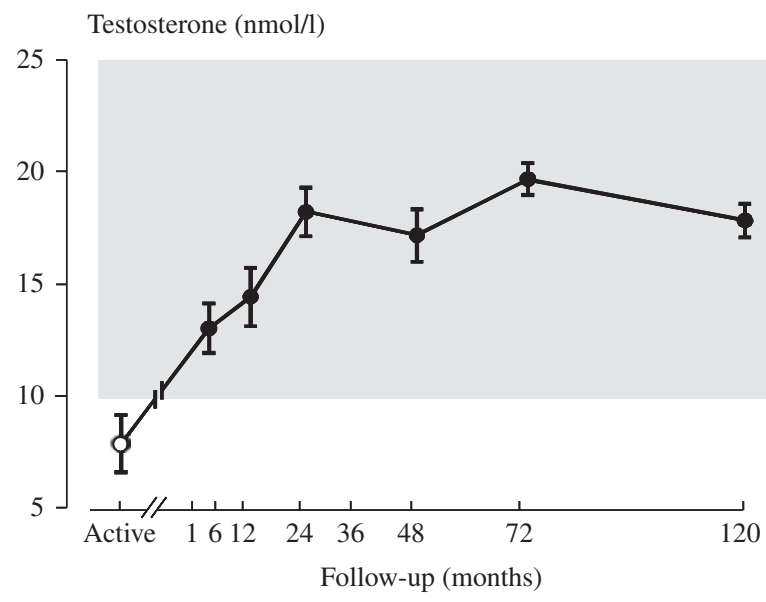

RBC counts $\left(\times 10^{12} / 1\right)$

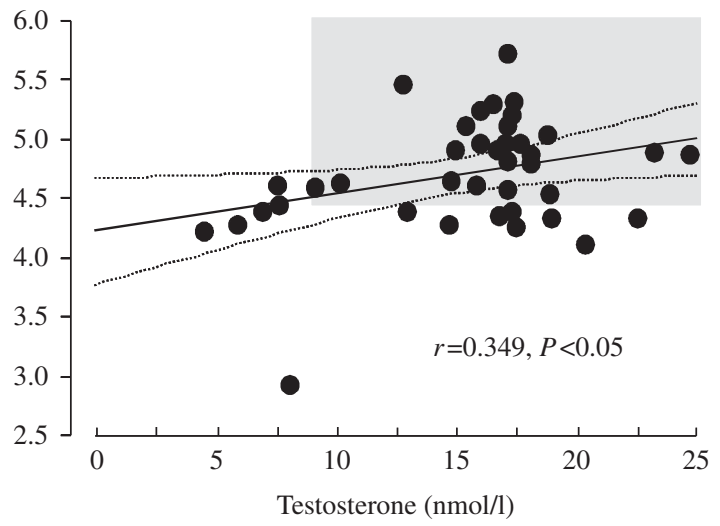

\section{Figure 4}

Mean testosterone levels in men with Cushing's disease before and after surgical remission (upper panel); correlation between testosterone levels and red blood cell (RBC) counts in men after remission of hypercortisolism (lower panel; solid line represents regression, dashed lines represent $95 \%$ slope confidence limits). Normal ranges are represented by the grey area. 
forming units and peripheral RBC markers (2). From a clinical viewpoint, glucocorticoids are the mainstay of treatment for Diamond-Blackfan anaemia, i.e. congenital erythroid precursor aplasia, with most patients increasing their haemoglobin levels on steroid therapy and some even reaching treatment independence (5).

Our study is the first to report on RBC parameters in a large series of patients with Cushing's disease, thus exploring changes in the erythroid compartment occurring during long-term exposure to excess cortisol levels. Our findings indicate that changes are clearly genderdependent, with men with Cushing's disease presenting low-normal RBC counts and haemoglobin concentration and women, on the contrary, presenting normal, if slightly above average peripheral erythroid cell counts. This distribution is the reversal of RBC parameters in the normal population and substantiates findings reported in a small group of patients with Cushing's disease (9). Common causes of anaemia, e.g. piles, gastric ulcer, intestinal bleeding, were not prevalent in either sex and are unlikely to contribute to the current finding as they would conceivably affect men and women with Cushing's disease in an equal manner. Still, the possibility of men with Cushing's disease presenting a greater prevalence of mild blood gastrointestinal loss cannot be excluded and warrants a thorough investigation, i.e. endoscopy, faecal occult blood testing, in future studies. Interestingly, cessation or dwindling of menses was not associated with changes in erythroid parameters, thus menstrual blood loss does not appear to contribute significantly to RBC mass in women in Cushing's disease.

Altogether, this suggests that women with endogenous hypercortisolism are sensitive to the erythroid expansive effect of corticosteroids and may explain the fact that - as the wide majority of patients with Cushing's disease is female - patients are commonly referred to as 'ruddy cheeked'. Conversely, factors other than cortisol excess per se modulate the erythroid compartment in men with Cushing's disease and one likely culprit is hypogonadism. Low testosterone is a very common sign of Cushing's syndrome in men $(22,23)$ due to the known inhibitory effect of excess cortisol on the hypothalamopituitary-gonadal axis. On the other hand, testosterone is an important determinant of erythropoiesis and contributes to the gender-related differences in erythroid parameters in adults (10). Further, administration of testosterone to hypogonadal men leads to a marked increase in haemoglobin level $(24,25)$ through a variety of effects on erythroid precursor cells, iron absorption and, possibly, erythropoietin synthesis (11). In our series, testosterone levels were mostly decreased in patients with Cushing's disease and strongly correlated with both haemoglobin and RBC counts, thus pointing to a direct link between low testosterone levels and low RBC parameters. This link was also evident in the postoperative recovery phase, as both testosterone and erythroid parameters normalised slowly and in a parallel fashion. These findings support the contention that testosterone rather than excess cortisol - modulates RBC mass in men with Cushing's disease. Another hormone known to modulate erythroid proliferation is $\mathrm{GH}$ and, indeed, $\mathrm{GH} /$ insulin-like growth factor 1 (IGF1) are involved in proliferation and maturation of erythroid progenitors (26). In keeping, erythropoiesis may be impaired in patients with GH deficiency (27) and haemoglobin levels, reticulocyte counts and erythropoietin concentrations increase on replacement therapy with $\operatorname{rhGH}(28,29)$. Patients with Cushing's disease are notably GH deficient $(30,31)$ and we had previously reported that defects in the GH-IGF1 axis are more persistent in men in remission after transsphenoidal surgery (15), possibly again connected to persistent hypogonadism. In fact, all male patients tested for $\mathrm{GH}$ deficiency after surgery were $\mathrm{GH}$ deficient compared with only $2 / 3$ of women in remission.

This study highlights yet another difference in the clinical presentation between male and female patients with Cushing's disease. We had first reported that men with this disorder display a more severe clinical presentation than their female counterparts some 10 years ago (12) and our findings have since been confirmed by other investigators $(32,33)$. Of interest, some of the more severe clinical features in men, e.g osteoporosis and vertebral fractures, can clearly be connected to low testosterone secretion (34).

This study was aimed at exploring possible derangements of erythroid cells in patients with Cushing's disease and thus comprised the most relevant parameters, as assessed by standard haematology coulter analysis. Our results pave the way to further in-depth evaluations of RBC homoeostasis, including iron, folate or vitamin B12 deficiency, reticolocyte counts and erythroid lifespan, in order to canvass features of anaemia in male patients with Cushing's disease and lead to targeted therapeutical approaches.

In contrast to erythroid cells, no gender-related differences were observed in the expected increase in WBC. Higher cortisol levels are associated with higher WBC and neutrophil counts in several conditions, e.g. ischaemic stroke, labour and exercise-related stress, although a significant correlation between these variables 
could not always be demonstrated (35). On the other hand, testosterone plays a minor role in the modulation of WBC (36). Leukocyte counts and percentages of neutrophils and eosinophils were normalised promptly after remission of hypercortisolism in patients with leukocytosis in the active phase, thus proving a good marker for cure in these patients.

In conclusion, we observed significant genderdependent differences in this first large-scale study on erythroid status in patients with Cushing's disease. Men with Cushing's disease present low RBC and haemoglobin levels, are frequently anaemic and require a lengthy recovery prior to normalisation of erythroid parameters after remission of hypercortisolism. These changes were associated with low testosterone levels both in the active phase and after remission. Conversely, women with Cushing's disease are slightly polycythaemic, independent of menstrual status. Close monitoring and further studies are warranted in order to further define its characteristics.

\section{Supplementary data}

This is linked to the online version of the paper at http://dx.doi.org/10.1530/ EJE-13-0824.

\section{Declaration of interest}

The authors declare that there is no conflict of interest that could be perceived as prejudicing the impartiality of the research reported.

\section{Funding}

This research did not receive any specific grant from any funding agency in the public, commercial or not-for-profit sector.

\section{References}

1 Wessely O, Deiner EM, Beug H \& von Lindern M. The glucocorticoid receptor is a key regulator of the decision between self-renewal and differentiation in erythroid progenitors. EMBO Journal 199716 267-280. (doi:10.1093/emboj/16.2.267)

2 Bauer A, Tronche F, Wessely O, Kellendonk C, Reichardt HM, Steinlein P, Schütz G \& Beug H. The glucocorticoid receptor is required for stress erythropoiesis. Genes and Development 199913 2996-3002. (doi:10.1101/gad.13.22.2996)

3 Hattangadi SM, Wong P, Zhang L, Flygare J \& Lodish HF. From stem cell to red cell: regulation of erythropoiesis at multiple levels by multiple proteins, RNAs, and chromatin modifications. Blood 2011118 6258-6268. (doi:10.1182/blood-2011-07-356006)

4 Reichardt HM, Kaestner KH, Tuckermann J, Kretz O, Wessely O, Bock R, Gass P, Schmid W, Herrlich P, Angel P et al. DNA binding of the glucocorticoid receptor is not essential for survival. Cell 199893 531-541. (doi:10.1016/S0092-8674(00)81183-6)

5 Vlachos A, Ball S, Dahl N, Alter BP, Sheth S, Ramenghi U, Meerphol J, Karlsson S, Liu JM, Leblanc T et al. Diagnosing and treating DiamondBlackfan anaemia: results of an international clinical consensus conference. British Journal of Haematology 2008142 859-876. (doi:10.1111/j.1365-2141.2008.07269.x)

6 Walsh D \& Avashia J. Glucocorticoids in clinical oncology. Cleveland Clinic Journal of Medicine 199259 505-515. (doi:10.3949/ccjm.59.5.505)

7 Cushing $\mathrm{H}$. The basophil adenomas of the pituitary body and their clinical manifestations. Johns Hopkins Bulletin 193250 137-195.

8 Gursoy A, Dogruk Unal A, Ayturk S, Karakus S, Nur Izol A, Bascil Tutuncu N \& Guvener Demirag N. Polycythemia as the first manifestation of Cushing's disease. Journal of Endocrinological Investigation 200629 742-744.

9 Dusek T, Kastelan D, Solak M, Basik Kinda S, Aganovic I \& Korsic M. Polycythemia as the first manifestation of Cushing's disease. Journal of Endocrinological Investigation 200831940.

10 Shahidi NT. Androgens and erythropoiesis. New England Journal of Medicine 1973289 72-80. (doi:10.1056/NEJM197307122890205)

11 Bachman E, Travison TG, Basaria S, Davda MN, Gou W, Li M, Westfall JC, Bae H, Gordeuk V \& Bhasin S. Testosterone induces erythrocytosis via increased erythropoietin and suppressed hepcidin: evidence for a new erythropoietin/hemoglobin set point. Journal of Gerontology 2014. In press. (doi:10.1093/gerona/glt154)

12 Pecori Giraldi F, Moro M, Cavagnini F \& the Study Group of the Italian Society of Endocrinology on the Pathophysiology of the Hypothalamic-Pituitary-Adrenal Axis. Gender-related differences in the presentation and course of Cushing's disease. Journal of Clinical Endocrinology and Metabolism 200388 1554-1558. (doi:10.1210/ jc.2002-021518)

13 Invitti C, Pecori Giraldi F, De Martin M, Cavagnini F \& the Study Group of the Italian Society of Endocrinology on the Pathophysiology of the Hypothalamic-Pituitary-Adrenal Axis. Diagnosis and management of Cushing's syndrome: results of an Italian multicentre study. Journal of Clinical Endocrinology and Metabolism 199984 440-448. (doi:10.1210/ jcem.84.2.5465)

14 Nieman LK, Biller BMK, Findling JW, Newell-Price J, Savage MO, Stewart PM \& Montori VM. Diagnosis of Cushing's syndrome: an Endocrine Society clinical practice guideline. Journal of Clinical Endocrinology and Metabolism 200893 1526-1540. (doi:10.1210/ jc.2008-0125)

15 Pecori Giraldi F, Andrioli M, De Marinis L, Bianchi A, Giampietro A, De Martin M, Sacco E, Scacchi M, Pontercorvi AS \& Cavagnini F. Significant GH deficiency after long-term cure by surgery in adult patients with Cushing's disease. European Journal of Endocrinology 2007 156 235-241. (doi:10.1530/eje.1.02329)

16 Rosner W, Auchus RJ, Azziz R, Sluss PM \& Raff H. Utility, limitations, and pitfalls in measuring testosterone: an Endocrine Society position statement. Journal of Clinical Endocrinology and Metabolism 200792 405-413. (doi:10.1210/jc.2006-1864)

17 Beutler E \& Waalen J. The definition of anemia: what is the lower limit of normal of the blood hemoglobin concentration? Blood $2013 \mathbf{1 0 7}$ 1747-1750. (doi:10.1182/blood-2005-07-3046)

18 Golde DW, Bersch N \& Cline MJ. Potentiation of erythropoiesis in vitro by dexamethasone. Journal of Clinical Investigation $1976 \mathbf{5 7} 57-62$. (doi:10.1172/JCI108269)

19 Kelly JJ, Martin A \& Whitworth JA. Role of erythropoietin in cortisolinduced hypertension. Journal of Human Hypertension 200014 195-198. (doi:10.1038/sj.jhh.1000959)

20 von Lindern M, Zauner W, Mellitzer G, Steinlein P, Fritsch G, Huber K, Löwenberg B \& Beug H. The glucocorticoid receptor cooperates with the erythropoietin receptor and c-Kit to enhance and sustain proliferation of erythroid progenitors in vitro. Blood 199994 550-559.

21 Udupa KB, Crabtree HM \& Lipschitz A. In vitro culture of proerythroblasts: characterization of proliferative response to erythropoietin and steroids. British Journal of Haematology $1986 \mathbf{6 2}$ 705-714. (doi:10.1111/ j.1365-2141.1986.tb04094.x)

22 Vierhapper H, Nowotny P \& Waldhausl W. Production rates of testosterone in patients with Cushing's syndrome. Metabolism 200049 229-231. (doi:10.1016/S0026-0495(00)91429-X) 
23 Luton JP, Thieblot P, Valcke JC, Mahoudeau J \& Bricaire H. Reversible gonadotropin deficiency in male Cushing's disease. Journal of Clinical Endocrinology and Metabolism 197745 488-495. (doi:10.1210/ jcem-45-3-488)

24 Snyder PJ, Peachey H, Berlin JA, Hannoush P, Haddad G, Dlewati A, Santanna J, Loh L, Lenrow DA, Holmes JH et al. Effects of testosterone replacement in hypogonadal men. Journal of Clinical Endocrinology and Metabolism 200085 2670-2677. (doi:10.1210/jcem.85.8.6731)

25 Coviello AD, Kaplan B, Lakshman KM, Chen T, Singh AB \& Bhasin S. Effects of graded doses of testosterone on erythropoiesis in healthy young and older men. Journal of Clinical Endocrinology and Metabolism 200893 914-919. (doi:10.1210/jc.2007-1692)

26 Merchav S, Tatarsky I \& Hochberg Z. Enhancement of erythropoiesis in vitro by human growth hormone is mediated by insulin-like growth factor I. British Journal of Haematology 198870 267-271. (doi:10.1111/ j.1365-2141.1988.tb02480.x)

27 Christ ER, Cummings MH, Westwood NB, Sawyer BM, Pearson TC, Sönksen PH \& Russel-Jones D. The importance of growth hormone in the regulation of erythropoiesis, red cell mass, and plasma volume in adults with growth hormone deficiency. Journal of Clinical Endocrinology and Metabolism 199782 2985-2990. (doi:10.1210/jcem.82.9.4199)

28 Ten Have SMTH, van der Lely AJ \& Lamberts SWJ. Increase in haemoglobin concentrations in growth hormone deficient adults during human recombinant growth hormone replacement therapy. Clinical Endocrinology 199747 565-570. (doi:10.1046/j.1365-2265.1997.3241124.x)

29 Sohmiya M \& Kato Y. Effect of long-term administration of recombinant human growth hormone (rhGH) on plasma erythropoietin (EPO) and haemoglobin levels in anemic patients with adult GH deficiency. Clinical Endocrinology 200155 749-754. (doi:10.1046/j.1365-2265.2001.01417.x)
30 Smals AE, Pieters GF, Smals AGH, Benraad TJ \& Kloppenborg PWC. Human pancreatic growth hormone-releasing hormone fails to stimulate human growth hormone both in Cushing's disease and Cushing's syndrome due to adrenocortical adenoma. Clinical Endocrinology 198624 401-407. (doi:10.1111/j.1365-2265.1986. tb01644.x)

31 Tzanela M, Karavitaki N, Stylianidou C, Tsagarakis S \& Thalassinos N. Assessment of GH reserve before and after successful treatment of adult patients with Cushing's syndrome. Clinical Endocrinology 200460 309-314. (doi:10.1046/j.1365-2265.2004.01976.x)

32 Valassi E, Santos A, Yaneva M, Tóth M, Strasburger CJ, Chanson P, Wass JAH, Chabre O, Pfeifer M, Feelders RA et al. The European Registry on Cushing's syndrome: 2-year experience. Baseline demographic and clinical characteristics. European Journal of Endocrinology 2011165 383-392. (doi:10.1530/EJE-11-0272)

33 Zilio M, Barbot M, Ceccato F, Vamozzi C, Bilora F, Casonato A, Frigo AC, Albiger N, Daidone V, Mazzai L et al. Diagnosis and complications of Cushing's disease: gender-related differences. Clinical Endocrinology 2014. In press. (doi:10.1111/cen.12299)

34 Tauchmanovà L, Pivonello R, Di Somma C, Rossi R, De Martino MC, Camera L, Klain M, Salvatore M, Lombardi G \& Colao A. Bone demineralization and vertebral fractures in endogenous cortisol excess: role of disease etiology and gonadal status. Journal of Clinical Endocrinology and Metabolism 200691 1779-1784. (doi:10.1210/ jc.2005-0582)

35 Deutsch V, Lerner-Geva L, Reches A, Boyko V, Limor R \& Grisaru D. Sustained leukocyte count during rising cortisol level. Acta Haematologica 2007118 73-76. (doi:10.1159/000103216)

36 Oertelt-Prigione $\mathrm{S}$. The influence of sex and gender on the immune response. Autoimmunity Reviews 201211 A476-A485. (doi:10.1016/j. autrev.2011.11.022)

Received 8 October 2013

Revised version received 16 December 2013

Accepted 20 December 2013 